\title{
Perspectivas da Psicologia Ambiental
}

\author{
Eda Terezinha de Oliveira Tassara \\ Elaine Pedreira Rabinovich \\ Universidade de São Paulo
}

A Psicologia Ambiental (PA) não tem um passado muito longo, podendo ser datada da década de 1960, com um ápice entre 1967-1973 (Pol, 2001, p. 57), mas denota uma ativa preocupação quanto ao seu futuro. Ao final dos anos 1980, vários estudiosos já se debruçavam sobre a constituição da PA em seus respectivos países.

Concomitantemente ao seu início como grupo de pesquisa, o Laboratório de Psicologia Sócio-Ambiental e Intervenção (Lapsi) organizou um simpósio, no I Encontro de Psicologia Ambiental no X Encontro Nacional da Associação Brasileira de Psicologia Social, em 1999, convidando representantes do Brasil, América Latina e Europa, para que apresentassem os fundamentos históricos da Psicologia Ambiental, correspondendo, respectivamente, às intervenções de José Pinheiro, Esther Wiesenfeld e Enric Pol (Tassara, 2001).

O recurso ao exercício da auto-análise histórica pode ser atribuído a vários motivos que podem ser subdivididos em: a PA e a demanda social; a PA e a brecha da Psicologia; a PA e a interdisciplinaridade.

\section{A psicologia ambiental e a demanda social}

Diversamente de outras áreas, a PA sempre esteve ligada às demandas sociais. Na Europa, por exemplo, a Psicologia Ambiental teve os seus inícios associados às questões arquiteturais e de planejamento urbano devidas à fase de reconstrução das cidades e reorganização social que se seguiu à II Guerra Mundial.

No Brasil, Maria do Carmo Guedes foi uma pioneira no gênero, tendo participado do planejamento de cidades nos anos 1960, dentro de um outro contexto: o surgimento de um Brasil que pretendia tornar presente o eterno "Brasil, país do futuro".

Nos EUA, a mudança de Kurt Lewin para esse país trouxe a experiência pioneira de Roger Barker e o conceito de behavior setting. Posteriormente, contudo, de acordo com a caracterização sócio-política do país, houve uma tendência a uma concentração em temas mais centrados no indivíduo.

Pol (2001, p. 55) se pergunta para quem e a quem serve a Psicologia Ambiental. O Lapsi, por ocasião do I Encontro, fez a mesma pergunta e, para respondê-la, abriu um espaço de locução para discutir a que veio a Psicologia Ambiental. Este espaço ocorreu nos três dias do evento, ocupando cerca de duas horas, ao qual compareceram 100 pesquisadores; além da multiplicidade de profissões ali representadas, o foco da temática foi a questão do ambientalismo.

A questão ambiental, atrelada à Educação Ambiental, parece ter sido, e continua a ser, um dos estopins do interesse pela área. Por tudo o que temos observado, vivido e protagonizado, a demanda social no Brasil atual se dirige para a área do ambientalismo e da intervenção.

\section{A psicologia ambiental e a brecha na psicologia}

Uma segunda linha de raciocínio de porque olhar para o futuro parece ser uma resposta a angústias ligadas ao presente se deve à fragilidade intrínseca da área. De um lado, emerge devido às lacunas que a psicologia, em geral, não consegue preencher nem responder; de outro, e pelo mesmo motivo, tem dificuldades óbvias de se estruturar como uma área, disciplina ou sub-área ou sub-disciplina.

Para Pol (2001, p. 55), a disciplina de Psicologia Ambiental começa a partir da relevância do objeto, abandona-a como discussão acadêmica dentro de um desenvolvimento lógico interno de questionamentos teóricos que alimentam a vida acadêmica, e depois tenta reencontrar tal relevância perdida.

De fato, devido à motivação do pesquisador vir da demanda social, estando atrelada a questões pragmáticas, há esse embate entre a teoria e a prática que ocorre, desta vez, dentro da própria teoria-prática.

Como decorrência desta fragilidade conceitual, a psicologia ambiental surge como um estranho no ninho de seus pares, o que incentiva um "colégio invisível” de pesquisadores que se auto-retroalimentam. Este circuito, além de não favorecer o desabrochar e o aparecimento da área dentro do cômputo geral, tem uma outra conseqüência: a evasão permanente de pessoas para áreas afins já constituídas.

A Psicologia, em geral, não entende a necessidade de uma psicologia que se autodenomina ambiental, argumentando que toda psicologia compreende o aspecto ambiental. Por outro lado, pode-se contra-argumentar que a psicologia em geral esvaziou o ambiente de seus conteúdos e concretude, donde a necessidade de uma área da psicologia que atentasse ao ambiente considerado daquele modo.

Em simpósio recentemente realizado (São Paulo, 2002) sob o tema do papel da Psicologia Ambiental, pudemos apreender que, sob a urgência de uma resposta a questões sociais candentes na sociedade brasileira, encontrava-se uma discussão que data da origem da separação entre os conhecimentos hoje denominados ciência, arte, religião. Tratava-se, de fato, de um anseio de ver reintegrados aspectos da pessoa e do ambiente, que foram desintegrados por meio desta separação e das que a elas se seguiram. Tratava-se de um anseio de que a Psicologia Ambiental viesse a ter a pessoa e o ambiente indissociáveis como objeto de estudo. O significado do termo religião - re-ligare, ligar de novo, pode ser apreendido dentro desta nova dinâmica que, em seu bojo, faz emergir a questão ambiental e a psicologia ambiental sob este "novo" 
ângulo ou perspectiva: um desafio epistemológico e hermenêutico.

\section{A psicologia ambiental e a interdisciplinaridade}

O acima dito leva à terceira linha de raciocínio: a psicologia ambiental foi, desde a sua origem, interdisciplinar, ou seja, respondeu a anseios de outras áreas e partilha, com elas, campos comuns.

Se, evidentemente, a psicologia ambiental não pode cumprir com a expectativa de re-ligar o que foi há muito separado, o seu pendor interdisciplinar não favorece igualmente a sua constituição como área. Antes, favorece uma crise de caráter epistemológico, com uma decorrência importante de tipo metodológico, que já esteve presente nos anos 1970, entre modelos oponentes de produção de conhecimento científico.

Se a PA na Europa pode se valer e se sustentar no conceito de sustentabilidade definida como a possibilidade de garantir um futuro comum, no Brasil, dificilmente acreditamos que este futuro comum nos inclua, a não ser como consumidores, inclusive deste conceito.

O conceito de sustentabilidade, contudo, permite operacionalizar a dimensão política e social, assim como o comportamento gerado por valores como a solidariedade e a fraternidade.

A decorrência pragmática de que é a gestão ambiental um ISO atribuído em escala mundial - quem vai garantir tal sustentabilidade parece implicar em um novo higienismo, aplicando regras morais por meio de práticas, agora, ambientais.

Face ao exposto, é nossa posição a de que a Psicologia Ambiental deve, no futuro, se posicionar quanto a: a questão ambiental e psicologia; ambientalismo e intervenção. Apresentaremos, a seguir, a nossa compreensão atual destes temas.

\section{A questão ambiental e a psicologia}

O desenvolvimento das teses ambientalistas deriva de uma concepção que, surgida dentro dos cânones do pensamento behaviorista, deslocou a visão do objeto para a relação pessoa-ambiente ou para o ambiente em relação ao sujeito. O ambiente passa a se configurar como fortemente ligado à visão empirista ou à dialética, não apenas na PA, mas dentro de um desenvolvimento histórico das concepções sujeito-objeto.

Deriva daí uma concepção que busca saber como as manifestações materiais constituem elementos da subjetividade, de um modo mais interno ou mais externo ou mais focado na interação.

O ambiente objetivo não é o ambiente do sujeito, mas o substrato de como o ambiente vai se tornar algo do sujeito. Trata-se de analisar a construção da subjetividade em seu aporte material: como, de que forma, porque o ambiente objetivo se constitui em ambiente subjetivo, o que não distingue, portanto, a PA da Psicologia Social.

A percepção ambiental é um fenômeno psicossocial. É como o sujeito incorpora as suas experiências. Não há leitura da objetividade que não seja ou não tenha sido compartilhada; o sujeito sempre interpreta culturalmente e, a partir daí, constitui-se como identidade. Sua identidade será como se espacializa, como se temporaliza, como constrói as narrativas de si próprio a partir desta espacialização e desta temporalização.

Deste modo, o objeto do estudo não pode ser nem só da PA nem da psicologia social: em ambos, tal objeto é a dimensão da transformação social da objetividade ambiental em subjetividade.

Esta compreensão inclusiva necessariamente implica em uma abordagem interdisciplinar.

\section{Ambientalismo e intervenção}

Assim como na França se fala hoje em partidos do movimento como os que desejam mudanças, em contraposição aos partidos que desejam a manutenção do status quo (JeanPierre Goubert, comunicação pessoal, 2003), o ambientalismo é um movimento social que pode ser pensado como um guarda-chuva de movimentos sociais que visam a mudança social, quer por meio da incorporação da população, quer por meio de movimentos sociais.

Na medida em que o objeto de estudo é necessariamente interdisciplinar, a metodologia utilizada deve ser a intervenção, quer devido à complexidade do objeto quer ao caráter de aspiração a mudanças dos movimentos sociais sobre a relação sujeito-ambiente.

Desta maneira, a temática é trazida para o social sensu stricto, colocando um ponto de vista estritamente político: se tal objeto existe, dentro de uma visão de ciência radical, só pode estar ligado à dimensão política para que a relação objetivo-subjetivo se torne cada vez mais objeto de controle do próprio sujeito. Isto implica em uma dimensão concomitantemente ética e política, com o risco de seu desaparecimento, caso tal não ocorra.

\section{Referências}

Pol, E. (2001). Ejes de tensión y nueva agenda para la Psicología Ambiental. Una perspectiva europea. In E. T. O. Tassara (Org.), Panoramas interdisciplinares: para uma psicologia ambiental do urbano (pp. 51-67). São Paulo: EDUC / FAPESP.

Tassara, E. T. O. (Org.). (2001). Panoramas interdisciplinares: para uma psicologia ambiental do urbano. São Paulo: EDUC / FAPESP.

Eda Terezinha de Oliveira Tassara, Doutora em Psicologia Experimental pela Universidade de São Paulo, é professora associada no Instituto de Psicologia, Universidade de São Paulo e coordenadora do Laboratório de Psicologia Sócio-Ambiental e Intervenção-I.P./USP.

Elaine Pedreira Rabinovich, Doutora em Psicologia Social pela Universidade de São Paulo, é pesquisadora no Laboratório de Psicologia Sócio-Ambiental e Intervenção-I.P./USP.

Endereço para correspondência: Eda T. O. Tassara, Av. Prof. Mello Moraes, 1721; Cidade Universitária; São Paulo/SP; 05508-030 - Brasil. Tel. (11) 3091-5024. Fax (11) 3091 4459. E-mail: lapsi@edu.usp.br 